\title{
Avaliação técnica e econômica de diferentes grupos genéticos de bovinos de corte machos superprecoces e do sistema de produção em confinamento
}

\author{
[Technical and economic evaluations of different genetic groups of yearling beef cattle males \\ and of the feedlot production system ] \\ I.C. Ferreira ${ }^{1,4}$, M.A. Silva ${ }^{2,4^{*}}$, F.A. Barbosa ${ }^{1}$, A.D.F. Carvalho ${ }^{3,4}$, G.S.S. Correa ${ }^{1,4}$, \\ A.B. Fridrich ${ }^{1,4}$, J.E.R. Souza ${ }^{1}$ \\ ${ }^{1}$ Aluno de pós-graduação - EV-UFMG - Belo Horizonte, MG \\ ${ }^{2}$ Escola de Veterinária - UFMG \\ Caixa Postal 567 \\ 30123-970 - Belo Horizonte, MG \\ ${ }^{3}$ Aluno de pós-graduação - ESALQ-USP - Piracicaba, SP \\ ${ }^{4}$ Bolsista CNPq
}

\begin{abstract}
RESUMO
Avaliaram-se as variáveis técnicas e econômicas do sistema de produção em confinamento de 88 animais superprecoces (sete meses de idade) pertencentes a três grupos genéticos, com 23 animais Charolês x Nelore, 26 Red Angus x Nelore e 39 Abeerden Angus x Nelore. Foram registrados pesos no inicio do confinamento e ao abate, duração do confinamento, ganhos de peso no período e diário dos animais e, por meio de conceitos econômicos e operacionais, foram calculados os custos de produção. O modelo estatístico utilizado na análise das variáveis incluiu efeitos do grupo genético e do peso inicial como covariável. Não houve diferença entre grupos genéticos para peso ao abate e ganho de peso diário. A duração do confinamento foi menor para animais Charolês x Nelore (159 dias), intermediária para Red Angus x Nelore (170 dias) e maior para Abeerden Angus x Nelore (178 dias). Os custos total, operacional e variável da diária foram 1,$02 ; 0,85$ e 0,89 US\$/dia, respectivamente. O confinador obteve lucro de 0,01 US $\$ / \mathrm{kg}$ e rentabilidade de $1,8 \%$ /mês. Não houve diferenças $(\mathrm{P}>0,05)$ entre grupos genéticos para custos, receita, margens bruta e líquida, lucro e rentabilidade.
\end{abstract}

Palavras-chave: custo de produção, desempenho, gado de corte, grupo genético, rentabilidade

\begin{abstract}
This experiment was carried out to evaluate technical and economic parameters for feedlot production system of 88 seven-month-old animals of three genetic groups (23 Charolais $x$ Nellore, 26 Red Angus $x$ Nellore, and 39 Aberdeen Angus x Nellore). Production traits (initial and slaughtering weights, number of days in feedlot, and total and daily weight gains) were recorded and costs were estimated using operational and economic concepts. The statistical model used to analyze the traits included the fix effect of genetic group and initial body weight as a covariate. No differences were observed among the genetic groups for slaughtering weight and daily weight gain. Number of days in feedlot was low for Charolais $x$ Nellore (159 days), intermediate for Red Angus x Nellore (170 days), and high for Aberdeen Angus $x$ Nellore (178 days) animals. Total, operational, and variable costs were 1.02; 0.85; and 0.89 US\$/day. Farmer profit was $0.01 \mathrm{US \$} / \mathrm{kg}$ and profitability/month was $1.78 \%$. Significant differences among the genetic groups were not observed for cost, income, gross and net margins, profit, and profitability.
\end{abstract}

Keywords: beef cattle, genetic group, production cost, performance, profitability

Recebido em 16 de junho de 2008

Aceito em 3 de dezembro de 2008

*Autor para correspondência (corresponding author)

E-mail: martinho@vet.ufmg.br 


\section{INTRODUÇÃO}

A produção de carne por bovinos superprecoces aumenta a eficiência do sistema de produção com redução do ciclo produtivo e maior fluxo de capital (Sampaio et al., 2002), além de melhorar a lucratividade e permitir significativo aumento da produção e da qualidade da carne. Entretanto, há necessidade de se utilizarem animais que apresentem melhor capacidade de conversão alimentar e habilidade de ganho de peso (Vargas Junior et al., 2002). Na literatura brasileira, já foram realizados trabalhos, como os de Restle et al. (1997) e Euclides Filho et al. (2003), que apenas quantificaram o desempenho e compararam grupos genéticos ou categorias. Existem poucos trabalhos na literatura que estabelecem uma relação entre o desempenho produtivo dos animais e o econômico. Dentre eles, merecem destaque o registrado por Silveira et al. (2004), que associa o desempenho técnico aos custos de produção de animais precoces e superprecoces, e o de Vittori et al. (2007), que agregam o desempenho ponderal ao financeiro, de animais não superprecoces.

Ao se confinarem bovinos superprecoces, explorase o período de maior eficiência alimentar dos animais, conforme observado por Silveira et al. (2004). De modo geral, as avaliações de sistemas de produção de animais superprecoces, pertencentes a diferentes grupos genéticos, não incluem informações individuais que permitam estabelecer associações das variáveis de desempenho produtivo às de desempenho econômico, à exceção dos trabalhos realizados por Ferreira et al. (2004), que avaliaram custo de produção e margem bruta de animais precoces e superprecoces, e Vitorri et al. (2007), que obtiveram custo de produção de animais não superprecoces de diferentes grupos genéticos.

A falta de informação que associa o desempenho técnico ao econômico de animais superprecoces norteou a realização deste trabalho, que teve como objetivo avaliar o desempenho técnico e econômico do sistema de produção de confinamento de bovinos machos superprecoces, pertencentes a diferentes grupos genéticos.

\section{MATERIAL E MÉTODOS}

Os dados foram obtidos de confinamento de bovinos machos superprecoces, desmamados aos sete meses de idade, confinados e abatidos, em média, aos 13 meses de idade, provenientes de uma propriedade localizada no município de
Esmeraldas, região central do Estado de Minas Gerais.

Três grupos genéticos de machos foram avaliados e pesados individualmente, sendo 23 animais Charolês x Nelore, 26 Red Angus x Nelore e 39 Abeerden Angus x Nelore, com médias de pesos iniciais de 216,5, 205,3 e 184,8kg, respectivamente. Foram formados três lotes com animais do mesmo grupo genético.

O confinamento foi realizado no período de 20 de junho a 16 de dezembro, com abates dos animais que atingiam aproximadamente $420 \mathrm{~kg}$, nos dias 22 , 25 e 26 de novembro e 05,12 e 16 de dezembro de 2004, com média de 170 dias de confinamento. Os animais foram alimentados três vezes ao dia, às $6 \mathrm{~h}$, $10 \mathrm{~h} 30 \mathrm{e} 15 \mathrm{~h}$.

Para estimar o consumo médio de MS por lote, com objetivo de precisar o cálculo do custo de produção, foram feitas medidas a cada três semanas, amostrando-se $10 \%$ da área de cocho de cada lote no momento do fornecimento do alimento. $\mathrm{O}$ alimento foi coletado e pesado em todos os fornecimentos do dia, durante três dias. A sobra de cada lote foi pesada, na manhã seguinte, antes da primeira alimentação dos animais por amostragem de $20 \%$ da área de cocho, fazendo, assim, a média de consumo por lote e atribuindo esse valor para o período.

A mesma dieta era oferecida a todos os animais com proporção média volumoso:concentrado, na MS, de 60:40, sendo que os $60 \%$ eram compostos de $33,8 \%$ de silagem de sorgo, $19,4 \%$ de cana-deaçúcar e $6,8 \%$ de milho verde planta inteira picada. O concentrado foi composto de $70 \%$ de milho, $15 \%$ de farelo de soja, 9,5\% de farelo de arroz, 2,5\% de núcleo mineralizado, $1 \%$ de calcário, $2 \%$ de ureia, resultando em teores de $20 \%$ de PB e $76 \%$ de NDT.

As instalações, constituídas de currais a céu aberto e corredor de manejo central com pista de alimentação lateral, disponibilizavam, em média, $13,5 \mathrm{~m}^{2}$ de área e $57 \mathrm{~cm}$ de cocho por animal.

As variáveis de desempenho registradas durante o confinamento foram peso ao início do período de confinamento, ganho de peso diário, peso ao abate, período de confinamento.

Foi realizado levantamento do inventário da propriedade e da estrutura do confinamento, curral de manejo com balança, bebedouros, saleiros, caixa d'água, galpão de máquinas e de estoques, currais 
do confinamento, fábrica de ração, cercas, cochos, etc., além dos custos variáveis de manutenção das instalações, máquinas, veículos e equipamentos, gastos com concentrados, volumosos, minerais, ionóforos, produtos veterinários, combustíveis, lubrificantes, mão-deobra, assistência técnica, impostos e taxas.

As informações de ganho de peso diário, peso ao abate, ganho de peso no período, duração do confinamento foram analisadas por meio do modelo:

$\mathrm{Y}_{\mathrm{ij}}=\mu+\mathrm{GG}_{\mathrm{i}}+\mathrm{b} \mathrm{X}_{\mathrm{ij}}+\mathrm{e}_{\mathrm{ij}}$, em que:

$\mathrm{Y}_{\mathrm{ij}}=$ observação do animal j sobre ganho diário, peso de abate no confinamento, tempo de confinamento no grupo genético i;

$\mu=$ constante;

$\mathrm{GG}_{\mathrm{i}}=$ efeito do grupo genético $\mathrm{i}$, sendo i de 1 a 3 ;

$\mathrm{b}=$ coeficiente de regressão linear da variável dependente em relação ao peso no início do confinamento;

$\mathrm{X}_{\mathrm{ij}}=$ peso do animal $\mathrm{j}$ ao início do confinamento do grupo genético $i$;

$\mathrm{e}_{\mathrm{ij}}=$ erro associado a cada observação.

As médias foram comparadas pelo teste StudentNewman-Keuls, a $5 \%$ de probabilidade pelo PROC GLM do SAS/2000.

A análise de custos de produção foi realizada contemplando custo total de produção com custos fixos e variáveis utilizados por Reis (2002) e custo operacional proposto por Matsunaga et al. (1976).

Para determinar os custos de produção, foram utilizados conceitos econômicos e operacionais de custos fixos, variáveis, alternativos, operacionais efetivos e fixos, totais e médios, receita média, lucro e margem.

Nos custos operacionais efetivos, foram levados em consideração gastos com aquisição dos animais, produtos veterinários, alimentação, mão-de-obra mais encargos sociais, assistência técnica, horas de máquina para arraçoamento, outras taxas diversas, frete, reparos de equipamentos, benfeitorias e impostos. O custo variável total foi composto de custo operacional efetivo mais custo de oportunidade do capital variável. Os custos de oportunidade do capital variável incluíram remuneração do capital de giro (desembolsos) e do empresário. O custo operacional fixo considerou a depreciação de instalações, benfeitorias, máquinas, equipamentos e veículos que foi apropriada pelo método linear. O custo de oportunidade sobre o capital fixo considerou os juros sobre capital de benfeitorias, máquinas e equipamentos e remuneração da terra. Os custos de cada grupo genético foram estimados a partir do custo do confinamento, considerando desempenho e duração do confinamento individual e consumo por lote.

Para corrigir os preços dos fatores fixos e variáveis, utilizou-se o dólar como indexador no valor da época (US\$ $1=\mathrm{R} \$ 2,94$ ), fornecido pelo CEPEA (Série ..., 2006).

A receita foi obtida pelo preço de venda da arroba (20,40 US\$/@) multiplicado pelo peso de abate, considerando rendimento médio do lote somado ao valor de venda de esterco $(5,10$ US\$/t.). A produção de esterco foi calculada como $6 \%$ do peso corporal médio do período de confinamento com teor de matéria seca de 31,2\% (Rodrigues Filho et al., 2002). A margem bruta foi calculada pela diferença entre a receita e o custo operacional efetivo, e a margem líquida pela diferença entre a receita e o custo operacional total. $O$ lucro foi obtido pela diferença entre a receita e os custos totais (soma de todos os custos, incluindo o custo do capital empatado na atividade). A rentabilidade foi obtida pela razão entre margem líquida e capital total investido vezes 100 . E a lucratividade, pela razão entre lucro econômico e receita total vezes 100 (Nogueira, 2004).

Os índices econômicos (margem bruta, margem líquida e lucro) calculados para cada grupo genético também foram analisados pelo modelo estatístico (1).

Para a remuneração do capital de giro e de benfeitorias, máquinas e equipamentos, considerou-se a taxa de juros nominal da poupança, fornecida pelo Banco Central do Brasil (Poupança..., 2006) no período em que ocorreu o confinamento. $O$ custo da terra foi obtido considerando o valor de arrendamento do módulo confinamento sobre $10 \%$ da receita obtida com a venda dos animais em confinamento. A quantidade dos recursos fixos a serem depreciados foi dividida pelo período do 
confinamento e pelo número de animais analisados do confinamento. $\mathrm{O}$ gasto médio com reparos de máquinas e equipamentos foi considerado como $5 \%$ do valor mobilizado na aquisição dos mesmos (Gomes e Novaes, 1992). O cálculo de impostos foi $2,3 \%$ da receita com a venda dos animais para frigoríficos. Esse imposto é a Contribuição Especial da Seguridade Social Rural (CESSR), deduzido no momento da venda dos animais. A taxa de juros utilizada para remuneração do capital de giro e do capital imobilizado na atividade foi de $0,67 \%$, valor da remuneração de poupança nominal no período do confinamento. Atribuiu-se valor mensal de US\$1.000 para remuneração do empresário com dedicação de 1 hora na atividade por dia, proporcional ao número de animais analisados.

\section{RESULTADOS E DISCUSSÃO}

Os animais dos três grupos genéticos apresentaram pesos semelhantes ao abate, por este ter sido o critério utilizado para finalizar o confinamento (Tab. 1), mas com diferenciados períodos no confinamento $(\mathrm{P}<0,05)$. Efeito não significativo de grupo genético sobre peso ao abate de animais jovens em confinamento, com diferentes períodos, foi observado por Euclides Filho et al. (2001), que obtiveram $471 \mathrm{~kg}$ para $1 / 2$ Angus - 1/2 Nelore, com 117 dias de confinamento, e $476 \mathrm{~kg}$ para $1 / 2$ Simental - 1/2 Nelore, com 131 dias de confinamento. Ferreira et al. (2006) também não encontraram diferenças entre peso ao abate de animais confinados pertencentes aos grupos Charolês $(409,50 \mathrm{~kg})$, $5 / 8$ Charolês- $3 / 8$ Nelore $(412,30 \mathrm{~kg})$ e $11 / 16$ Charolês 5/16 Nelore $(434,50 \mathrm{~kg})$.

Os animais do grupo genético Abeerden Angus x Nelore, por conterem alta fração genética de animais de raça britânica, deveriam apresentar precocidade de terminação. A maior duração no confinamento desse grupo, no entanto, pode estar relacionada ao menor peso desses animais no início do confinamento e à definição do peso final como critério para abate dos animais. Segundo Cruz et al. (2004) e Pacheco et al. (2005), o menor tempo de confinamento está associado a animais que apresentam maior peso vivo no início do confinamento. Isto foi observado neste trabalho, ou seja, os animais do grupo Abeerden Angus x Nelore apresentaram maior tempo em confinamento e menor peso inicial, ao contrário do Charolês x Nelore, que apresentou maior peso inicial e menor período de confinamento. No sentido de reduzir os dias de confinamento, alguns trabalhos, como o de Ítavo et al. (2007), avaliaram opções para produzir bezerros mais pesados ao desmame cujo destino era o confinamento, sugerindo uso de suplementação exclusiva nessa fase.

O ganho de peso no período está associado à duração do confinamento e foi maior para os animais do grupo genético Abeerden Angus $\mathrm{x}$ Nelore e menor para animais Charolês x Nelore. O grupo Red Angus x Nelore apresentou ganhos por período semelhantes aos demais grupos.

Tabela 1. Número de observações em cada variável, desempenho ponderal, em $\mathrm{kg}$, e duração do confinamento, em dias, de animais de três grupos genéticos de bovinos de corte superprecoces em confinamento em 2004

\begin{tabular}{lllllll}
\hline Variável & $\mathrm{n}$ & $\mathrm{CHN}$ & $\mathrm{n}$ & $\mathrm{RAN}$ & $\mathrm{n}$ & $\mathrm{AAN}$ \\
\hline Peso corporal de entrada, $\mathrm{kg}$ & 23 & 216,51 & 26 & 205,35 & 39 & 184,18 \\
Peso de abate, kg & 23 & $420,87 \mathrm{a}$ & 26 & $424,07 \mathrm{a}$ & 39 & $419,00 \mathrm{a}$ \\
Duração do confinamento, dias & 23 & $159 \mathrm{c}$ & 26 & $170 \mathrm{~b}$ & 39 & $178 \mathrm{a}$ \\
Ganho de peso no período, $\mathrm{kg}$ & 21 & $209,09 \mathrm{~b}$ & 25 & $221,56 \mathrm{ab}$ & 38 & $233,94 \mathrm{a}$ \\
Ganho de peso diário, $\mathrm{kg}$ & 23 & $1,285 \mathrm{a}$ & 26 & $1,313 \mathrm{a}$ & 39 & $1,334 \mathrm{a}$ \\
\hline
\end{tabular}

Médias seguidas de letras distintas, na linha, diferem entre si pelo teste $\mathrm{SNK}(\mathrm{P}>0,05)$.

$\mathrm{CHN}=$ Charolês $\mathrm{x}$ Nelore; RAN $=$ Red Angus $\mathrm{x}$ Nelore; AAN $=$ Abeerden Angus $\mathrm{x}$ Nelore.

Não houve diferença entre grupos genéticos para o ganho de peso diário dos animais no confinamento, o que pode ser atribuído à diferente duração do confinamento e aos ganhos de peso por períodos diferenciados dos grupos genéticos. Signoretti et al. (2006) também alertaram para situações de ganhos de pesos diferenciados entre grupos quando há diferenças no manejo alimentar pré-confinamento, principalmente quando ocorrerem limitações qualitativa ou quantitativa de alimentos. No presente estudo, contudo, os animais receberam manejo alimentar semelhante tanto antes quanto durante o confinamento. Os resultados obtidos 
neste experimento são semelhantes aos observados por Pacheco et al. (2005), que não encontraram diferenças entre grupos genéticos para ganho diário de peso, ao avaliarem desempenho de grupos genéticos $5 / 8$ Charolês $\mathrm{x}$ 3/8 Nelore e 5/8 Nelore x 3/8 Charolês para animais superjovens, abatidos aos 15 meses, com $430 \mathrm{~kg}$, submetidos ao mesmo regime alimentar e ambiente.

Cruz et al. (2004), ao trabalharem com confinamento de bovinos jovens, encontraram diferenças para ganho de peso diário e período de confinamento entre os grupos genéticos Blonde d'Aquitane x Nelore, Canchim x Nelore, Limousin $\mathrm{x}$ Nelore, Piemontês $\mathrm{x}$ Nelore, Canchim e Nelore em três pesos fixos de abate. Os grupos genéticos eram oriundos de fazenda experimental e de diferentes propriedades, o que pode ter proporcionado ganhos diferenciados dos grupos, em razão de diferentes manejos préconfinamento, incluindo principalmente a qualidade da dieta. Da mesma forma, Urick et al. (1991a) observaram desempenhos diferentes para animais Angus x Hereford, Red Poll x Hereford, Pinzgauer $x$ Hereford, Simental x Hereford e Tarentaise- Hereford, abatidos aos 382 dias, ou com $400 \mathrm{~kg}$, ou com $12,7 \mathrm{~mm}$ de gordura de cobertura na carcaça, porém provenientes de dois ambientes.

A diferença entre grupos genéticos para ganho de peso diário até o abate dos animais pode ser advinda também do efeito materno, pois mães com menor produção de leite podem causar restrição quantitativa de alimento aos filhos e, em consequência, ganhos de peso e peso final diferenciados em animais superprecoces (Urick et al., 1991b). Entretanto, na presente pesquisa, essa restrição poderia ter sido alternativamente compensada pela suplementação dos bezerros antes do confinamento, ou também por não existir diferença significativa entre a produção de leite das mães que, entretanto, não foi mensurada.

O custo com alimentação foi 14,86; 13,93 e 14,01 US\$/@ para Charolês x Nelore, Red Angus x Nelore e Abeerden Angus x Nelore, respectivamente.

A avaliação econômico-financeira do confinamento indicou lucro com custo total médio de US\$1,37 e receita média, por quilograma, de US\$1,38. Nessa situação e a permanecer esse cenário, a tendência é o crescimento da atividade e a expansão da empresa.

O investimento só é indicado quando a relação benefício/custo for maior que 1 . $\mathrm{Na}$ presente pesquisa, para cada dólar investido houve retorno de 1 centavo de dólar (relação benefício/custo $1,01)$.

A rentabilidade $1,78 \%$ ao mês foi mais atrativa que a taxa de poupança, mas não atingiu os valores de maior remuneração no mercado. Já a lucratividade do $0,11 \%$ ao mês indicou, segundo Nogueira (2004), que os animais foram vendidos a $0,11 \%$ a mais que o custo total de produção, o que demonstrou, mais uma vez, lucro.

Os custos operacional efetivo, variável total e fixo total corresponderam a $89,3 \%, 92,7 \%$ e $7,2 \%$ do custo total. O alto custo fixo $(7,2 \%)$ indica a necessidade de se aumentar o número de animais para diluir os custos fixos. Custos fixos menores do que a 7,2\% do custo total foram observados por Lopes e Magalhães (2005), que estimaram custo fixo em $4,1 \%$ do custo total.

O custo operacional total foi $90,5 \%$ do custo total e o custo de oportunidade do capital fixo, $6,1 \%$ do custo total. Este último inclui os juros sobre capital de benfeitorias, máquinas $\mathrm{e}$ equipamentos e a remuneração da terra, e decorre do alto custo dos recursos fixos e do alto valor de remuneração da terra pelo tempo que os animais permaneceram confinados, que está diretamente relacionado ao arrendamento do módulo para confinamento. A compra de bezerros correspondeu a $48,1 \%$, o concentrado a $30,63 \%$ e o volumoso a $9,6 \%$ do custo operacional efetivo. Quanto ao custo total, a compra de bezerros contribuiu com 43,0\%, o concentrado com $27,4 \%$ e o volumoso com $8,6 \%$.

O baixo percentual atribuído à compra dos bezerros ocorreu em função do peso médio inicial $(199 \mathrm{~kg})$ dos animais. Mesmo com longo período médio de confinamento (170 dias), o percentual atribuído ao volumoso foi baixo e decorrente dos custos de produção menores que os de mercado, por peculiaridades da fazenda e, principalmente, em razão do custo da adubação. 
Os custos total, operacional e variável da diária foram 1,$02 ; 0,85$ e 0,89 US\$/dia. Esses valores são muito competitivos, em razão de o proprietário conseguir produzir silagem de sorgo a baixo custo $(27,89$ US\$/tonelada de matéria seca), enquanto o preço médio do período histórico foi 90 US\$/tonelada de matéria seca. Isso favoreceu o baixo preço da diária e, consequentemente, o lucro.
A análise econômico-financeira dos grupos genéticos está apresentada na Tab. 2. Não houve diferenças estatísticas entre grupos genéticos para todas as variáveis analisadas.

As receitas do Abeerden Angus $\mathrm{x}$ Nelore, Charolês x Nelore e Red Angus x Nelore foram $1,38 \mathrm{US} \$ / \mathrm{kg}$.

Tabela 2. Número de animais confinados (n), desempenho econômico, em US\$/ kg e \%/mês, de três grupos genéticos de bovinos de corte superprecoces, em confinamento, em 2004

\begin{tabular}{llcccccc}
\hline Variável & Unidade & $\mathrm{n}$ & $\mathrm{CHN}$ & $\mathrm{n}$ & $\mathrm{RAN}$ & $\mathrm{n}$ & AAN \\
\hline Custo operacional efetivo & US\$/kg & 23 & 1,24 & 26 & 1,23 & 39 & 1,22 \\
Custo operacional total & US\$/kg & 23 & 1,27 & 26 & 1,26 & 39 & 1,25 \\
Custo variável total & US\$/kg & 23 & 1,28 & 26 & 1,28 & 39 & 1,27 \\
Custo total & US\$/kg & 23 & 1,37 & 26 & 1,38 & 39 & 1,37 \\
Receita total & US\$/kg & 23 & 1,38 & 26 & 1,38 & 39 & 1,38 \\
Margem bruta & US\$/kg & 23 & 0,14 & 26 & 0,15 & 39 & 0,16 \\
Margem líquida & US\$/kg & 23 & 0,11 & 26 & 0,12 & 39 & 0,13 \\
Lucro & US\$/kg & 23 & 0,006 & 26 & 0,004 & 39 & 0,01 \\
Rentabilidade & $\% / \mathrm{mês}$ & 23 & 1,64 & 26 & 1,71 & 39 & 1,72 \\
Lucratividade & $\% / \mathrm{mês}$ & 23 & 0,08 & 26 & 0,12 & 39 & 0,12 \\
\hline
\end{tabular}

Não houve diferença entre grupos genéticos para nenhuma das variáveis analisadas, teste $\mathrm{SNK}(\mathrm{P}<0,05)$. $\mathrm{CHN}=$ Charolês x Nelore, RAN = Red Angus x Nelore, AAN = Abeerden Angus x Nelore.

As margens bruta e líquida foram positivas, porém não diferiram entre os grupos genéticos que apresentaram valores, em dólares por quilograma, de 0,$14 ; 0,16 ; 0,15$ e 0,$11 ; 0,13$ e 0,12 , respectivamente, para Charolês $\mathrm{x}$ Nelore, Abeerden Angus x Nelore e Red Angus Nelore. Os lucros foram positivos, 0,006 para Charolês $\mathrm{x}$ Nelore, 0,01 Abeerden Angus x Nelore e 0,004 para Red Angus x Nelore.

Os valores de rentabilidade mensal do Charolês $\mathrm{x}$ Nelore (1,64\%), do Red Angus x Nelore (1,71\%) e do Abeerden Angus x Nelore (1,72\%) foram semelhantes, porém mais atrativos que a taxa nominal de remuneração de poupança do período $(0,67 \%)$. Estes valores de rentabilidade foram similares aos obtidos por Cruz et al. (2004), que avaliaram rentabilidade mensal de animais em confinamento com 12 meses de idade, para três pesos ao abate $(400,440$ e $480 \mathrm{~kg})$, dos grupos genéticos $1 / 2$ Blonde d'Aquitane x $1 / 2$ Nelore $(1,9 ; 1,8$ e $1,3 \%), 1 / 2$ Limousin $\times 1 / 2$ Nelore $(2,2 ; 2,6$ e $1 \%), 1 / 2$ Piemontês x $1 / 2$ Nelore $(1,1$; $0,7$ e $0,8 \%)$, Canchim $(1,2 ; 0,2$ e $0,2 \%), 1 / 2$ Canchin x $1 / 2$ Nelore $(0,9,-0,3$ e $0,6 \%)$ e Nelore $(-1,1,-1,2$ e $-1,1 \%)$, respectivamente. Os resultados demonstram maior rentabilidade nos menores pesos de abate. Silveira et al. (2004) obtiveram rentabilidade de $4,1 \%$, maior que a estimada nesta pesquisa.

As lucratividades obtidas com os animais dos três grupos genéticos não apresentaram diferenças estatísticas com índices de 0,08; 0,12 e $0,12 \%$ para Charolês x Nelore, Red Angus x Nelore e Abeerden Angus x Nelore, respectivamente. Esses valores são numericamente pequenos e pouco atrativos para investimentos.

\section{CONCLUSÕES}

O desempenho econômico dos grupos genéticos Charolês $x$ Nelore, Red Angus x Nelore e Abeerden Angus x Nelore foi positivo e não diferiu entre os grupos. As lucratividades dos três grupos genéticos foram pequenas e pouco atrativas comparadas às de outros investimentos em pecuária. Bezerros devem ser desmamados com maior peso para encurtar o período de confinamento e reduzir os custos de produção de animais superprecoces. Evidencia-se a importância de se produzir volumoso a baixo custo para viabilidade econômica do confinamento. 


\section{AGRADECIMENTOS}

Ao Conselho Nacional de Desenvolvimento Científico e Tecnológico (CNPq) pela concessão da bolsa de estudos e por todo suporte para a realização deste trabalho.

\section{REFERÊNCIAS BIBLIOGRÁFICAS}

CRUZ, G.M.; ESTEVES, S.N.; TULLIO, R.R. et al. Peso de abate de machos não-castrados para produção do bovino jovem. 1. Desempenho em confinamento e custo de produção. Rev. Bras. Zootec., v.33, p.635-645, 2004.

EUCLIDES FILHO, K.; FEIJÓ, G.L.D.; FIGUEIREDO, G.R. Efeito de idade à castração e de grupos genéticos sobre desempenho em confinamento e características de carcaça. Rev. Bras. Zootec., v.30, p.71-76, 2001.

EUCLIDES FILHO, K.; FIGUEIREDO, G. R.; EUCLIDES, V.P.B. Desempenho de diferentes grupos genéticos de bovinos de corte em confinamento. Rev. Bras. Zootec., v.32, p.11141122, 2003.

FERREIRA, I.C.; SILVA, M.A.; REIS, R.P. et al. Análise de custos de diferentes grupos genéticos de bovinos de corte terminados em confinamento. Arq. Bras. Med. Vet. Zootec., v.56, p.385-391, 2004.

FERREIRA, J.J.; BRONDANI, I.L.; LEITE, D.T. Características de carcaça de tourinhos Charolês e mestiços Charolês -Nelore terminados em confinamento. Cienc. Rural, v.36, p.191-196, 2006.

GOMES, S.T.; NOVAES, L.P. Custo da produção de leite C-Estado de São Paulo. Brasília: Ministério da Agricultura Pecuária e Abastecimento, 1992. 59p.

ÍTAVO, L.C.V.; ÍTAVO, C.C.B.F.; SOUZA, S.R.M.B.O. et al. Avaliação da produção de bezerros em confinamento ou em suplementação exclusiva. Arq. Bras. Med. Vet. Zootec., v.59, p.948-954, 2007.

LOPES, M.A.; MAGALHÃES, G.P. Análise da rentabilidade da terminação de bovinos de corte em condições de confinamento: um estudo de caso. Arq. Bras. Med. Vet. Zootec., v.57, p.374379, 2005.
MATSUNAGA, M.; BEMELMANS, P.F.; TOLEDO, P.E.N. et al. Metodologia de custo de produção utilizada pelo IEA. Agric. S. Paulo, v.23, p.123-139, 1976.

NOGUEIRA, M.P. Gestão de custos e avaliação de resultados: agricultura e pecuária. Bebedouro: Scot Consultoria, 2004. 219p.

PACHECO, P.S.; RESTLE, J.; SILVA, J.H.S. et al. Desempenho de novilhos jovens e superjovens de diferentes grupos genéticos terminados em confinamento. Rev. Bras. Zootec., v.34, p.963-975, 2005.

POUPANÇA - rendimento nominal. Disponível em:

$<$ http//www.ipea.data.gov.br/ipeaweb/dll/ipeadat a?65370046/>. Acessado em 03/11/2006.

REIS, R.P. Fundamentos de economia aplicada. Lavras: UFLA, 2002. 95p.

RESTLE, J.; FLORES, J.L.C.; VAZ, F.N. et al. Desempenho em confinamento, do desmame ao abate aos quatorze meses, de bovinos inteiros ou castrados, produzidos por vacas de dois anos. Cienc. Rural, v.27, p.651-655, 1997.

RODRIGUES FILHO, M.; MANCIO, A.B.; GOMES, S.T. et al. Avaliação econômica do confinamento de novilhos de origem leiteira, alimentados com diferentes níveis de concentrado e de cama de frango. Rev. Bras. Zootec., v.31, p.2055-2069, 2002.

SAMPAIO, A.A.M.; BRITO, R.M.; CARVALHO, R.M. Comparação de sistemas de avaliação de dietas para bovinos no modelo de produção intensiva de carne. Confinamento de tourinhos jovens. Rev. Bras. Zootec., v.31, p.157163, 2002.

SÉRIE do dólar comercial para venda. CEPEA. Disponível em: $<$ http//www.cepea.esalq.usp.br/series/>. Acessado em 21 nov. 2006.

SIGNORETTI, R.D.; RESENDE, F.D.; SIQUEIRA, G.R. et al. Exploração do ganho compensatório como estratégia nutricional. In: ENCONTRO CONFINAMENTO: GESTÃO TÉCNICA E ECONÔMICA, 1., 2006, Jaboticabal. Anais... Jaboticabal: FUNEP, 2006. p.57-80.

SILVEIRA, A.C.; MARTINS, C.L.; ARRIGONI, M. D. B. et al. Produção do novilho superprecoce. In: SIMPÓSIO SOBRE 
BOVINOCULTURA DE CORTE, 5., 2004, Piracicaba. Anais... Piracicaba: FEALQ, 2004. p.227-241.

URICK, J.J.; MacNEIL, M. D.; REYNOLDS, W.L. Biological type effects on postweaning growth, feed efficiency and carcass characteristics of steers. J. Anim. Sci., v.69, p.490-497, 1991a.

URICK, J.J.; REYNOLDS, W.L.; KNAPP, B.W. Maternal breed of sire effects on postweaning performance of heifer and steer progeny: postweaning growth and carcass characteristics. J. Anim. Sci., v.69, p.4377-4387, 1991b.
VARGAS JUNIOR, F.M.; BONNECARRÉRE SANCHEZ, L.M.; PASCOAL, L.L. Desempenho de novilhos de corte alimentados com dietas contendo quantidades crescentes de concentrado associado à forragem de aveia (Avena strigosa) tratada com ureia. Arq. Bras. Med. Vet. Zootec., v.54, p.405-413, 2002.

VITORRI, A.; GESUALDI JUNIOR, A.; QUEIROZ, A.C. et al. Desempenho produtivo de bovinos de diferentes grupos raciais, castrados e não castrados, em fase de terminação. Arq. Bras. Med. Vet. Zootec., v.59, p.1263-1269, 2007. 